\title{
BMJ Open From strategy to action: a qualitative study on salient factors influencing knowledge transfer in project-based experiential learning in healthcare organisations in Kenya
}

Tecla Chelagat (D) , Joseph Onyango, Gilbert Kokwaro, Jim Rice

To cite: Chelagat T, Onyango J, Kokwaro G, et al. From strategy to action: a qualitative study on salient factors influencing knowledge transfer in projectbased experiential learning in healthcare organisations in Kenya. BMJ Open 2019;9:e031100. doi:10.1136/ bmjopen-2019-031100

- Prepublication history for this paper is available online. To view these files, please visit the journal online (http://dx.doi org/10.1136/bmjopen-2019031100).

Received 17 April 2019 Revised 19 August 2019 Accepted 21 August 2019

Check for updates

(C) Author(s) (or their employer(s)) 2019. Re-use permitted under CC BY-NC. No commercial re-use. See rights and permissions. Published by BMJ.

Institute of Healthcare Management, Strathmore University Business School, Strathmore University, Nairobi, Kenya

Correspondence to

Dr Tecla Chelagat;

tkivuli@strathmore.edu

\section{ABSTRACT}

Objectives Knowledge transfer is recognised as a key determinant of organisational competitiveness. Existing literature on the transfer of knowledge and skills imply diminutive return on investment in training and development due to the low application of learnt knowledge. Following devolution of health services provision to new counties in Kenya in 2013, Strathmore Business School designed an experiential facility improvement project-based leadership training programme for healthcare managers in the new counties. Selected healthcare management teams participated in the leadership training to improve health systems performance in the devolved counties in Kenya. Despite similar training, the projects implementation contexts were different, leading to different implementation completion rates. The aim of this study was to investigate the reasons for this disparity and then recommend solutions.

Design A qualitative study using semi-structured interviews. A thematic framework approach was used in data analysis.

Setting and participants Thirty-nine projects teams constituting; 33 successful and 6 unsuccessful project teams, were purposively selected based on their project implementation success rates at the end of the leadership training. The managers had undertaken a team-based institutional improvement project. The prioritised projects were housed within; 23 public, 10 faith-based and 6 private health facilities in 19 counties in Kenya.

Results Our findings indicate projects completion rates were influenced by (training design, work environment climate, trainee characteristics, team-based coaching and leveraging on occurring opportunities). Transfer barriers were (inadequate management support, inadequate team and staff support, high staff turnover, misalignment of board's verses manager's priorities, missing technical expertise, endemic strikes, negative politics and poor communication). Recommendations were (need-driven curriculum, effective allocation and efficient utilisation of resources, proper prioritisation, effective communication, longitudinal coaching and work-teams recruitment). Conclusion The findings reveal that unless training interventions are informed by a need-driven curriculum customised to real-world work teams, the potential knowledge and skill transfer can be thwarted.
Strengths and limitation of this study

- A high proportion of invited respondents participated in the study.

- This is the first qualitative inquiry study to explore the enablers and barriers of leadership development knowledge transfer in a healthcare context in the sub-Saharan Africa.

- The study lacked a comparison group, and therefore it is not possible to explicitly conclude that transferability of knowledge occurred as a result of the implementation of the training alone.

- This is a single site study and the findings could be transferred or adapted to similar project based experiential learning programme interested in transferring knowledge from class to real workplace challenges.

\section{BACKGROUND}

Training as an organisational practice has been recognised as the most common human resource strategy and solution for improving performance. ${ }^{1}$ From this point of view, the ultimate goal of any training is to ensure that knowledge is converted to tangible results in the workplace in order to increase organisational performance. Empirical studies on the transfer of knowledge and skills suggest a low return on investment in training and development because of weak knowledge application in specific work environments. ${ }^{2}$ Several studies have found it challenging to compare the learning transfers due to non-uniform evaluation models and approaches used. ${ }^{3}$ It is estimated that only about $10 \%$ to $15 \%$ of all training experiences are transferred from the training environment to the job. ${ }^{45}$ Another estimate puts training expenditure vis-a'-vis transfer as a skill loss of $87 \%$ to $90 \%$ of investment. $^{6}$ Additionally, Wexley and Latham ${ }^{7}$ estimated that approximately $40 \%$ of newly 
acquired training knowledge and skills is instantly lost after the training, then it drops to $25 \%$ after 6 months and $15 \%$ 1 year post-training. These estimates, however, differ from Saks and Belcourt ${ }^{8}$ evaluation on effective application of learnt knowledge from training on the job at three subsequent data point periods. Their findings indicated the approximated knowledge transfer at $62 \%, 44 \%$ and $34 \%$ immediately after training, 6 months and 1 year after training, respectively. This is an indicator that many organisations are not able to realise the return on investment (ROI) for training their employees due to underutilisation of learnt knowledge, skills and behaviours. Consequently, the exploration of knowledge application to work environments, and how it can be improved, is receiving increased importance among researchers and practitioners, especially in an era of scarce resources, accountability and dynamic business environment.

Ford $^{9}$ defined training transfer as 'the application continued by learners to the performance of jobs, individuals, community responsibilities of knowledge in learning activities'. Even though the transfer through the application of knowledge beyond the training is the prime purpose in knowledge development, it has been considered by some research as the most challenging goal to attain. ${ }^{10}$ Despite being a major research interest area for many scholars, understanding how to apply the results of the training process are limited..$^{11}$ The existing literature has so far identified three main determinants of training transfer complexity: training design (principle of learning, sequencing and training content), individual characteristics (ability, personality and motivation) and the work environment climate (support and opportunity to use). ${ }^{11}$ Studies by Tracey $e t a l^{12}$ and Blume et $a l^{13}$ on the application of trained skills on the job and the importance of the work environment have indicated that when employees perceive that the organisational climate is supportive, they are more likely to apply their new knowledge in the work environment. Still, other studies found non-significant relationships between a supportive environment and transfer of training. ${ }^{1415}$

Velada et $a l^{16}$ studied the effects of training design, individual characteristics and work environment on the transfer of knowledge. Their findings imply that for organisations to maximise their return on investment with regard to training and development, they need to focus on all three determinants of transfer of training: training design, individual characteristics and work environment. Transfer studies confirm that certain strategies are a crucial prerequisite for transfer because they are key mediators between influencing factors and transfer. ${ }^{17-20}$ Pham $e t a l^{2122}$ conducted studies on the effects of the work environment on the transfer of training from Master of Business Administration programme in Vietnam. The results showed key players of transfer training strategy as the trainees, training providers and employers. These studies suggest that there is a need to evaluate training with two levels of outcome: (i) training outcomes and (ii) transfer outcomes. ${ }^{23}$ However, a majority of training outcomes are measured during or just after the training programme on learning and retention of learnt knowledge. In contrast, transfer outcomes are evaluated by measuring how trained skills have been generalised and maintained by the trainee after being on the job for some time. ${ }^{24}$ These areas are the least considered during training design. Knowledge transfer at the workplace can, therefore, be improved if transfer outcomes are evaluated after the training and also if transfer enablers and barriers could be further unpacked.

Our study was guided by the concepts of dynamic interaction and emergent knowledge transfer factors drawn from the theoretical model for training transfer by Baldwin and Ford. ${ }^{5}$ Baldwin and Ford's model is widely recognised to be grounded on the idea that training transferability depends on training design, trainee characteristics and work environment. ${ }^{5}$ The model postulates that; (1) training design, (2) work environment (support on all levels, organisational climate both in the learning and transfer phase) and (3) trainee characteristics (personality, motivation) predict learning transfer. The general model is well supported by empirical data by Clarke and colleagues. ${ }^{25}{ }^{26}$ Our study utilises an analytical approach that recognises similar attributes such as design, trainee characteristics and work environment, but further explored and unpacked to understand how the identified attributes interact in different contexts. This approach fosters the development of rich explanations and a deeper understanding of the factors underpinning knowledge transfer in different health systems in Kenya.

\section{Kenya's health system in the context of devolution}

In 2010, Kenya's new constitution created a devolved system of government with 47 counties. Health service delivery was devolved to the counties in 2013. So far health system performance in Kenya remains poor. ${ }^{27}$ For example, the maternal mortality rate remains unacceptably high in Kenya. Kenya's maternal mortality ratio is currently estimated to be 362 for every 100000 live births. ${ }^{28}$ Most of the challenges are a result of poor health systems leadership. ${ }^{29}$ Devolution was meant to be the vehicle towards attainment of the WHO defined Millennium Development Goals number 3, 4, 5 and 6; the Sustainable Development Goal number 3 (health) and the social pillar (health) for vision 2030; by bringing health services and decision-making closer to people. ${ }^{30-32}$ Building strong and sustainable health systems, therefore, requires innovation, including innovative education for health workers. ${ }^{33}$ Understanding how to facilitate the development of effective leadership for health is, therefore, more crucial than ever. ${ }^{34}$

Our study is based on ongoing health managers training 'The Leading High-performing Healthcare Organisations' (LeHHO). The programme was developed and implemented in the year 2010 by Strathmore Business School in partnership with Management Sciences for Health and Ministry of Health, under the funding support by United 
States Agency for International Development. The aim of the programme is to enable Kenya's national and county health management teams address the most important health systems challenges in a devolved health system of government. The choice of the study programme was informed by the rationale that the programme was: (i) designed by a consortium of key stakeholders in health with the intention of addressing the devolved health system challenges, (ii) uniquely designed and integrated with team-coaching modules, which is a newly adapted concept in Kenya and most part of Africa, (iii) designed to suit all the health sector needs (public, private and the faith-based health facilities), (iv) planned with deliberate consideration on how monitoring and evaluation process could be implemented throughout the programme and (v) to the best of our knowledge, the first project-based experiential learning training to be evaluated post-devolution in Kenya. Although the LeHHO programme has now been going on for over 7 years with an aim of improving health systems performance in the devolved counties in Kenya, the question on implementation disparities among different teams warrants an inquiry. The leadership programme share similarities with most training programme whereby outcomes are measured during or just after the training programme, focusing on learning and retention of learnt knowledge. In contrast, transfer studies demonstrate that transfer outcome should be evaluated by measuring how trained skills have been maintained and generalised by the trainee after being on the job for some time. ${ }^{24}$ These are the evaluation areas least considered during training design and gaps in research that this study intended to fill.

The most recent and comparable cases studies on the impact of leadership on organisational performance in; upper Egypt by Mansour et al, ${ }^{35}$ Dangme West district in Ghana by Kwamie et $a l^{36}$ and Afghanistan by Seddiq et $a l,{ }^{37}$ reported positive impact of the leadership development training on the selected health indicators. These studies further demonstrated that there was positive sustainability and scaling up of the positive results beyond the training. A quasi-experimental study by Seims $e t a l^{88}$ on strengthening management and leadership practices to increase health-service delivery in Kenya reported positive impact of leadership training whereby the health service delivery indicators increased from $54 \%$ at baseline to $65 \%$ at endline, and $67 \%$ post-intervention, as compared with the control group and that the improvements were sustained at least for 6 years. These empirical review findings point to one conclusion; application of leadership management and governance practices, contribute to a positive impact on health systems. However, the understanding of how the attained knowledge was transferred from theory to practice at work environment is warranted. Additionally, all the highlighted studies were undertaken in public health facilities hence limiting the findings to the public health sector only. Another research gap is that the study participants and programme targets were the front-line health service providers, and hence generalisation of the findings is explicitly limited to service delivery health workers. Without the contextual transfer information, it is not possible to ascertain whether the programme is achieving its intended purpose, which is to equip leaders with knowledge, skills and practice to improve sustainable health system performance. Failure to address the health system performance which impacts on the counties socioeconomic status, we will not be able to attain the sustainable development goal number three (health) and the social pillar (health) in vision 2030. This can be achieved through timely and compelling evidence that links leadership development and health services provisions improvement for decision-makers to strengthen their health systems. In summary, the only way to achieve the devolved health system objective is through evidenced-based health system intervention. Without the evidence, it is more difficult to sustain and scale-up the best practices.

This study is part of a larger inquiry focusing on LeHHO programme alumni on the impact of leadership development on sustainable health systems performance'. For this study, 'knowledge transfer' was described as 'the extent of successfully implemented priority projects and realised project's indicators goals; with the aim of improving health systems performance in different counties in Kenya'. The objectives of the present study were to investigate the healthcare manager's perceptions on factors that facilitate or impede knowledge transfer at their workplace, with intentions of recommending possible strategies or informing policies for enhancing the transfer. In this study, we make two key contributions towards these objectives. First, we explore, summarise and present context-specific transfer enablers and barriers in diverse health systems settings. Second, we identify and bring to light proposed definite solutions for optimal transfer based on the participant's experiences. To elude ambiguity in measuring knowledge transfer, we opted to use a rigorous yet practically sound and relevant learning transfer measure. We focused on the action of transferring leadership development knowledge through practice and implementation of selected workplace priority challenge projects addressed by different teams. The projects provided practical relevance and most pertinent effectiveness measures with regard to the training curriculum content and transfer design. The study, therefore, sought to answer the following research questions:

a. What factors fostered knowledge transferability on the implementation of the prioritised projects at the workplace?

b. What factors impeded knowledge transferability on the implementation of the prioritised projects at the workplace?

c. What are the programmes' alumni recommended contextual knowledge transfer strategies for enhancing knowledge transfer during and after the training? 


\section{METHODS}

The sources of data for this qualitative study were derived from a broader research undertaken in 39 health facilities whose managers had participated in the LeHHO training. Each case health facility teams were purposively sampled to include; 23 public, 10 faith-based and 6 private identified through the LeHHO programme 2011 to 2016 programme reports. Based on the narrative reports from the 39 team-based projects, 33 of the 39 projects were successfully implemented following the LeHHO training, as defined by the teams challenge goal indicator set as a baseline at the beginning of the training. The project deliverables were defined by tangible assignments or products output required of project teams with the intention of removing key performance bottlenecks in their facilities through ownership and accountability. Examples of the projects desired measurable results (DMR) goals prioritised by the teams are: (i) have functional theatres and laboratories in Y County Hospital in place by 28 July 2014 and increase skilled deliveries from 185 to 200 per month and, (ii) have a fully automated laboratory in $X$ Mission Hospital by September 2014 and have it accredited by June 2015. The teams were expected to record the project desired measurable result in a challenge model format which indicates the 'current situation' and the 'expected outcome' in 9 month time. The identified project's indicators of interest were recorded in an action plan and monitored throughout the training period. Project teams were expected to present the progress of the project to the rest of the class at every module. The presentation session enabled participants to stay committed and accountable to the project, but at the same time, they receive feedback from other healthcare managers. The final project results were presented during the experience sharing workshop, attended by diverse healthcare stakeholders.

For sampling, three criteria informed the case project-teams selection. First, we ensured that the teams were a good representation for the public, private and faith-based health facilities within the 19 counties in Kenya. Second, the teams had identified and started the implementation and documented priority project progress. Third, there was at least one or more trained team member still working in the same organisation post-training. Within each of the facility teams, the units of analysis forming the basis of data gathering were the project team leaders or team representatives from the project teams. Interviews were undertaken, to gain an in-depth understanding of participant's perspectives and experiences on knowledge transfer at their facilities, as an institutional performance improvement initiative. The study participants were identified through the training institutional projects team reports retrieved from the Strathmore programmes shared files. All the project-team leaders and representatives were sent letters via email as an initial invitation to participate in the study. Follow-up telephone calls were made to confirm participation and then, book interview appointments for those who had expressed willingness to contribute to the study. Interviews were conducted using
Table 1 Participants demographic information

\begin{tabular}{llc}
\hline \multirow{2}{*}{ Item } & Category & $\begin{array}{l}\text { Frequency (No) } \\
\mathbf{8}(\%)\end{array}$ \\
\hline Health facility type & Public/government & $23(59 \%)$ \\
& Faith-based & $10(26 \%)$ \\
Sex & Private & $6(15 \%$ \\
Age category & Male & $16(41 \%)$ \\
& Female & $23(59 \%)$ \\
& $26-35 y e a r s$ & $4(10 \%)$ \\
Highest education & 36-45years & $13(33 \%)$ \\
level & B6-55years & $19(49 \%)$ \\
& $>55$ years & $3(8 \%)$ \\
& Master degree & $12(31 \%)$ \\
& Doctoral degree & $1(3 \%)$ \\
& Others & $3(8 \%)$ \\
\hline
\end{tabular}

This table depicted a summary of the study participant's demographic information and the health sector type. Source: survey data 2019.

an interview guide between August 2018 and December 2018.

\section{Demographic characteristics of participants}

From the 39 purposely selected team-based projects, a sum of $(n=23) 59 \%$ were from public health, $(n=10) 26 \%$ from the faith-based and $(n=6) 15 \%$ were from the private health facilities. The study participants comprised of 23 $(59 \%)$ females and $16(41 \%)$ male. Nearly half $(49 \%)$ of the participants were between the age category of 46 to 55 years. A total of $59 \%$ of the participants had a master's degree. Table 1 provides a summary of the study participant's characteristics.

\section{Data collection}

The researchers structured the questionnaire starting with introductory general questions such participant's current responsibilities and their general impression and experiences, during and after the training. The interviews then progressed to more mapped questions and probes on the implementation status of the projects post-training. The probes inquired more on factors which could have led to success or failure in the implementation of the projects at the workplace. The interviewer also sought information on work-environment specific enablers and barriers of knowledge transfer, and how these factors could be reinforced or mitigated for better results. We specifically focused on their experiences during project implementation, which consequently presented opportunities for immediate knowledge application and linked classroom with the work environment challenges. To mitigate potential bias and ensure consistency during the interview, the interview questionnaire was piloted with four project teams who were not included in the study 
sample. The exercise was done jointly by the principal investigator Tecla Chelagat (TC) and the research assistant AnnieMuisyo (AM). The selection of the research assistant was not only informed by her technical expertise but also we ensured she had no prior knowledge of the programme or interaction with the programme alumni. In total, 39 in-depth face-to-face interviews were conducted. Again, the first four interviews were jointly undertaken by the principal investigator and the research assistant at the respondent's health facilities, and rest (35 interviews) were undertaken singly by the research assistant. Each interview session lasted between $45 \mathrm{~min}$ to $75 \mathrm{~min}$. The interviews were recorded using portable recorders and supplementary notes were taken during the interview. ${ }^{39}$ Daily debrief was done by AM and TC to monitor any emerging issues or concerns that needed urgent attention.

\section{Ethical considerations}

Written informed consent was obtained from the participants prior to their interview participation. The participants were informed about voluntary participation and assured anonymity. To ensure data security, all the printed research materials were kept in a locked room within the health facilities and the training institution. The leadership knowledge transfer data were not considered as personal data as per NACOSTI and Strathmore University Ethics Review Committee approval since the study did not involve human biological material.

\section{Data analysis}

The data analysis was conducted by the first author (TC) and the second author (JO). The recorded interviews were transcribed verbatim and verified for accuracy by TC and JO. The transcripts were clustered to public, private and faith-based facilities, and then analysed separately per health sector. Each transcript was read independently and the emerging codes and themes were analysed by TC and JO. We adopted a thematic framework approach to identify and organise data according to the emerging key themes. Even though the initial codes were deductively drawn from the research questions, emerging codes from the iterative transcriptions were drawn inductively through line by line coding. Data management was aided by the use of NVivo V.10 software package. Data were classified and organised according to emergent key themes and subthemes such as different types of work environment factors. We cross-examined the emerging key themes for consistency with the literature. The themes from each cluster were further compared with Baldwin and Ford's conceptual framework themes on factors affecting training transfer. ${ }^{40}$ Illustrative quotes representing a range of health manager's views were highlighted to elucidate each theme for reporting.

\section{Indirect patient and public involvement}

This study was done without direct patients and public participation. The health managers played an active role in reporting on priority projects implementation experiences through interviews. Health managers also facilitated dissemination of research findings through alumni breakfast forum and institutional breakfast series. PowerPoint slides were shared with respective institutions through the programme alumni.

\section{RESULTS}

Major themes

\section{Factors influencing knowledge transfer in the healthcare context}

Our findings indicate that there were two broad categories of projects completion rates; projects that were completed on time and those that were not completed on time. For those projects that were completed on time, five main transfer themes enablers that illustrated the experiences of the managers emerged. Three of these themes were consistent and largely reflected the established categories represented in the literature for major transfer influences such as Baldwin's and Ford's conceptual model. The themes were; (i) training design, (ii) trainee characteristics and (iii) work environment. These results are in general agreement with significant standing findings in the area of training knowledge transfers. Additionally, two unique themes; (i) team-based coaching and (ii) occurring opportunities emerged. Further analysis led to the emergence of new subthemes such as attitudinal shift, power, position and political goodwill. Events such as devolution of health systems, endemic strikes in public health systems and political elections were categorised as the subthemes in the occurring opportunities. Table 2 displays a summary of enablers according to health facility type.

\section{Enabler 1: training design}

In all the three settings (public, private and faith-based facilities), managers identified the quality of the training design as the most critical factor influencing knowledge transfer at work environment. The relevance of curriculum content and team-based coaching that followed classroom-based training facilitated timely implementation of the projects. Baldwin and Ford found out that some of the critical training design factors include; the training curriculum or content, the learning approach and the structure of the training activities. ${ }^{24}$

'...the training curriculum was very relevant to my personal and workplace needs, the training enabled us to identify a real challenge that was specific to our organisational need ... under-delivery was not an option' (Health manager at a public health facility).

Curry $e t a l^{41}$ cite that "when trainers realise that they are being evaluated by the amount of transfer that occurs, their training strategies will change and they will strive to transfer knowledge, rather than simply to entertain 
Table 2 Enablers of knowledge transfer per health sector

\begin{tabular}{|c|c|c|c|}
\hline Facility type facilities & Public health facilities & & \\
\hline Main theme & Subtheme & Faith-based facilities & Private health \\
\hline Training design & $\begin{array}{l}\text { Relevant content } \\
\text { Peer-cross learning visits } \\
\text { Experiential training curriculum }\end{array}$ & $\begin{array}{l}\text { Applicable knowledge to } \\
\text { workplace problem-based } \\
\text { learning }\end{array}$ & $\begin{array}{l}\text { Case methodology } \\
\text { Impact-oriented training }\end{array}$ \\
\hline Trainee characteristics & $\begin{array}{l}\text { Attitudinal shift } \\
\text { Improved communication skills } \\
\text { Self-awareness }\end{array}$ & $\begin{array}{l}\text { Improved leadership } \\
\text { competencies } \\
\text { Personal leadership }\end{array}$ & $\begin{array}{l}\text { Ability to lead a team } \\
\text { Self-leadership }\end{array}$ \\
\hline $\begin{array}{l}\text { Work environment } \\
\text { climate }\end{array}$ & $\begin{array}{l}\text { Teamwork } \\
\text { Buy-in across the institution } \\
\text { Power and position } \\
\text { Political goodwill }\end{array}$ & $\begin{array}{l}\text { Teamwork } \\
\text { Buy-in by management and } \\
\text { board }\end{array}$ & Board members approvals \\
\hline Team-based coaching & $\begin{array}{l}\text { Inspired hearts through team } \\
\text { coaching }\end{array}$ & Coaching support & $\begin{array}{l}\text { Coaching focused on results } \\
\text { attainment }\end{array}$ \\
\hline
\end{tabular}

This table illustrated factors enabling knowledge transfer in orders recurring responses according to the health facility type. Training curriculum design, management buy-in, teamwork, team coaching, devolution, industrial strikes emerged as key enablers for transfer. Source: survey data 2018.

trainees'. This observed among the managers as illustrated in these quotes;

'LeHHO programme is an impact-oriented training which ensures that classroom learning and acquisition of new skills alone is not adequate, but it should be demonstrated through practice and application of knowledge (...). We learnt to objectively analyse challenging situations then develop an actionable plan which in-turn catalysed the success of our project...'

(Health manager at a private facility).

It is evident from these comments that training effectiveness is determined by the thoroughness of the need assessment and the transfer intervention methods for before, during and after the training.

\section{Enabler 2: trainee characteristics}

Studies have found individual trainee characteristics such as personality traits, motivation level and ability to apply learnt knowledge and expectations from the training to be associated with a transfer of knowledge post-training. Our study data highlighted three trainee characteristics that are deemed significant predictors of transfer of knowledge to workplace challenges: (i) Motivation level, (ii) ability to apply knowledge and (iii) training expectations. These enablers were echoed across represented project teams during the interviews;

'... my ability to lead a team was a great enabler, as the head of human resources...I learnt to communicate effectively and listen more to my team members, thus we formed a highly effective team which was unstoppable.' (Health manager at a private facility).

'...I am a trained doctor, and the only language I know is the technical language ... (this is the problem, how do I fix it?)...the training enabled me to learn more about myself, now that I have self-awareness, I am confident that I can lead an effective team because I am a better leader who can enable others to face challenges...' (Health manager at a public facility).

\section{Enabler 3: work environment}

Majority of the healthcare managers described their work environment climate including, support by board members and buy-in across the institution as a significant learning transfer enabler. Power and position was a uniquely emerging subtheme; those trainees who were in top leadership positions were able to facilitate timely implementation of projects. Another unique contextual enabler was political goodwill; in those counties where there was political support from the county government, projects were implemented on time;

'...teamwork fostered positive work climate and effective communication during project implementation...being at the position of governance in our county enabled me to influence our juniors' buy-in on a shared vision. Additionally, we had all the necessary resources from human resource to finances.'

(Health manager at a public facility).

Participants reported the political aspiration towards quality and accessible healthcare for all Kenyans as a key enabler for learning transfer. One participant noted that one of the key concerns for many county governors was the provision of quality healthcare services. This was a critical measure by the followers to measure their leader's worthiness for their votes. 
'...the political goodwill for the public and a private partnership was a great enabler for our project...it increased access and utilisation of outpatient and inpatient services...this was made possible due to the launch of National Health Insurance Fund (NHIF) cards for private-sector health services cover.' (Health manager at a private facility).

\section{Enabler 4: team-based coaching}

The increasing body of literature on coaching as a leadership development tool presents leadership coaching as a promising leadership development and has become a widely used intervention for leadership development. ${ }^{42}$ Coaching, therefore, is a means of supporting team improve performance, and the processes through reflection and dialogue. ${ }^{43}$ The team coach provides an objective view of the team and facilitates conversations that enable the team to adjust their ways of working together in service of their goals. ${ }^{44}$ Even though team coaching embedded in the training is delivered only in four sessions through the entire training, participants associated the coaching sessions with the success of their projects. This is evident in the following quotes;

'Our lecturers and coaches motivated us even when we felt we will not achieve the project goals...the training really challenged and inspired us...consequently we inspired our nurses and other staff at the maternity, antenatal department, thus contribution to effective community mobilisation.' (Health manager at a public facility).

'...leadership knowledge and skill in business management gained from healthcare management course enabled us to work effectively as teams resulting in successful project implementation at workplace... the coaching sessions significantly increased the effectiveness of the programme in that our coach visited our work environment and kept the connection even after the implementation of the project.' (Health manager at a faith-based facility).

\section{Enabler 5: occurring opportunities}

Riding on existing gains and opportunities were cited as key enablers. Participants alluded to the saying 'success is when preparation meets opportunity'. Participants felt that their ability to scan their work environment and prioritise a challenge to be addressed as a catalyst project enabled them to consciously look at the gains and resources within their means. Ironically, some of the opportunities included industrial strikes, devolution and increased number of trained managers within the organisation. Absence of industrial disputes during the implementation period facilitated completion of the implementation of projects in the private sector facilities, compared with some public facilities that were affected by nurses' strikes;

'...nurse's strike was an opportunity for the private sector due to increased patient load...our project enabled us to establish and operationalised digital medical record for both inpatient and outpatient to ensure fast turn-around time...we wouldn't have prioritised the need if it was business as usual with low patient load...' (Health manager at a private facility).

'...Devolution brought decision-making and services closer to the people, therefore, health management teams are able to reach out to the county management team for support, and this worked... devolution works well also for patients in that they are now only a phone call away from airing their grievances to the county governor whenever their healthcare needs are not met...' (Health manager at a public facility).

'...our team had one major enabler that led to the successful implementation of our institutional improvement project, 'devolution of the health systems'... devolved funds from the central government to county-level made it easy to access adequate resources to carry out projects...' (Health manager at a public facility).

'...our institution has heavily invested in capacity building of health managers... we are consistently paying fees for a minimum of four participants every year to attend the LeHHO training...each team has been able to implement a new project...this has accelerated the implementation of the strategic plan priorities leading to more gains than anticipated...' (Health manager at a faith-based facility).

\section{Factors that impeded implementation of the prioritised projects at the workplace per sector}

For those projects that were not completed on time, the following were the main unique contextual barriers: (i) inadequate management support in provision of necessary resources for implementation, (ii) inadequate team and staff support, (iii) high staff turnover, (iv) misalignment of board's verses manager's priorities, (v) missing technical expertise required to implement the projects, (vi) endemic strikes, (vii) negative politics and (viii) poor communication management. Table 3 presents a summary of the knowledge transfer barriers according to the health facility type.

Impeder 1: inadequate management support in the provision of necessary resources for implementation

Those teams that did not have trainees in senior management positions did not get adequate management support to implement the projects.

'The buy-in by the management was a great challenge... I was the only trained manager from my institution and no one in my department or other related department was willing to get involved... the board approved the project, however, there was a challenge in working together with other staff.' (Health manager at a public facility). 
Table 3 Impeders of knowledge transfer per health sector

\begin{tabular}{|c|c|}
\hline Institution type & Impeding factors \\
\hline $\begin{array}{l}\text { Public health } \\
\text { facilities }\end{array}$ & $\begin{array}{l}\text { Management buy-in and support } \\
\text { Poor communication skills } \\
\text { Human resource constraints (recruiting, } \\
\text { training and retaining). } \\
\text { Inadequate relevant expertise } \\
\text { Endemic industrial action by nurses } \\
\text { and doctors }\end{array}$ \\
\hline $\begin{array}{l}\text { Faith-based health } \\
\text { facilities }\end{array}$ & $\begin{array}{l}\text { Devolution (moving of staff) contributed } \\
\text { to high staff turnover in both public and } \\
\text { faith-based facilities } \\
\text { Lack of board members support } \\
\text { Lack of coaching post-training }\end{array}$ \\
\hline $\begin{array}{l}\text { Private health } \\
\text { facilities }\end{array}$ & $\begin{array}{l}\text { Political interference } \\
\text { Poor prioritisation }\end{array}$ \\
\hline
\end{tabular}

This table presented a summary of factors impeding knowledge transfer in orders recurring responses according to the health facility type. Management support and team support, human resources constraints, communication and negative politics were considered as key barriers for transfer.

Source: survey data 2018.

\section{Impeder 2: inadequate team and staff support}

Inability to influence teams and the rest of the staff greatly affected the success rate of project implementation.

'Our project was on improving staff retention...however devolution worsened the process because some staff left for county health facilities after the devolution of healthcare services... most of the transferring staff were unwilling to fill the exit form that would help identify challenges encountered...' (Health manager at a faith-based facility).

\section{Impeder 3: high staff turnover and poor retention}

It was reported by the public and faith-based facilities that the rate of staff turnover was a great impediment to the implementation of the projects. In those teams where there was high staff turnover following the training, implementation of projects was delayed.

'... our organisation as whole accepted changes for the improvement of services ...we achieved the project goal by automating the patient medical records management system, however, it is worth mentioning that utilisation dropped by $35 \%, 6$ months after implementation (...). Despite positive changes, our biggest challenge is staff retention; we train our nurses and are immediately absorbed in the big public or private hospitals.' (Health manager at a faith-based facility).

\section{Impeder 4: misalignment of board's verses manager's priorities}

A subgroup of respondents identified misalignment of priorities managers priorities with the boards' and the existing resources as a key challenge. Where there was a misalignment between Board and Management priorities, then implementation was delayed.

'...even though the pressing priority need was establishing a human resources policy manual resources as a strategy towards recruiting, engaging and retaining our staff especially nurses; our board members did not support operationalisation of the developed policy document... our project was just not in the list of board's priorities...so we have shelved our manual until when the time is right.' (Health manager at a faith-based facility).

\section{Impeder 5: missing technical expertise required to implement the projects}

Some project required technical expertise that was not readily available at the facilities, thus delaying implementation of the projects.

'...let's say our greatest challenge was inadequate expertise...our project was anchored on technology, but the IT personnel in our institution lacked adequate capacity and relevant expertise to implement the project... this was worsened by scope creep, because automation involved different department and yet I was the only manager attending the training, this caused a major impediment from the onset of the project...' (Health manager at a public facility).

\section{Impeder 6: endemic strikes}

Public health facilities were characterised by constant health worker strikes due to poor working conditions, staff shortage and low salaries.

'Industrial action by nurses and doctors was a big challenge and we couldn't achieve our projects' DMR, which was focusing on increasing antenatal fourth visit by pregnant women... without the frontline health services staff, our hospital became 'ghost town' ... our project remained on paper and was never actualised...' (Health manager at a public facility).

\section{Impeder 7: negative politics}

The challenge of promises for new development in exchange for a vote compounded by scarce and mismanagement of resources due to corruption was cited as a key barrier.

'Failure to actualise our project was hinged on political interference and prioritisation (...). The project involved working with county governments...even though some county boards shot down the projects, those who accepted lacked the will and commitment to prioritise and allocate the necessary resources.' (Health manager at a private facility). 


\section{Impeder 8: poor communication management}

Inadequate communication skills and people management was constantly reported as a key barrier to teamwork hence poor project results.

'...I realised our biggest challenge is not lack of adequate resource but how we communicate with one another...I hold a technical rather than managerial position and tagging along with other departments into my project from initiation was critical...' (Health manager at a public facility).

\section{Suggestions on context-specific best practices and strategies for enhancing training transfer}

The managers felt that their experiences during the training have equipped them with new knowledge and skills such. To optimise transfer and the training outcome in diverse health systems in Kenya, the programme alumni proposed the following strategies: (i) effective allocation and efficient utilisation of resources especially the financial and human resource, (ii) prioritisation of intervention in alignment with organisational priorities, resources and staff input, (iii) effective communication among partners for buy-in, (iv) longitudinal coaching post-training and (v) training the pre-existing workplace teams.

\section{Strategy 1: effective allocation and efficient utilisation of resources (financial and human resource)}

Poor allocation and utilisation of resources such as finance and human resources were identified as a key challenge in healthcare management.

'Addressing human resources for health challenges such as recruitment, engagement and retention of personnel especially the nurses is the best way towards tackling implementation issues and promote sustainability and scaling up of good practices.' (Health manager at a private facility).

\section{Strategy 2: prioritisation of intervention in alignment with organisational priorities, resources and staff input}

Managers recommended that the ultimate measure of transfer should not focus on the project implementation results only, but other areas of improvement within the institutions which could be also attributed to leadership training.

'We did not succeed to implement our project; however I benefited greatly from the personal coaching and wish they could be explored more (...). My suggestion on how to improve the training to support the actualisation of projects is through the provision of assistance on how to select the 'right' project that fits institutional needs...involving all the stakeholders and departments from the onset of training...this can be achieved with the support of the training institution.' (Health manager at a faith-based facility).
Strategy 3: effective communication among the key stakeholders

Evidently, communication among partners and within institutions especially during the change process is critical. The shared vision should be well-articulated and communicated to all stakeholders to ensure adequate buy-in and support during implementation.

'Communication and buy-in was a major impediment to the success of our project (...). I suggest that Strathmore Business School going being a training institution and champions of leadership and governance, to act as a bridge in such projects in order to attain goodwill from the county management.' (Health manager at a private facility).

\section{Strategy 4: longitudinal coaching}

Another significant finding of this study is that the participants were concerned with the coaching engagements duration.

'Coaching sessions were definitely effective and very recommendable...but I would say they were ended 'prematurely' at the end of the training when some action plans implementation had just started (...). I, therefore, pose this question to Strathmore Business School, 'How can you partner closely with our institutions to ensure continuity and institutionalisation of coaching session beyond the training period?' (Health manager at a faith-based facility).

\section{Strategy 5: training pre-existing workplace teams}

Another proposed area of possible intervention was an emphasis on team recruitment from the same institution to ensure continuity of knowledge, speedy buy-in and continuous implementation of the activated projects.

'I would recommend strict adherence to team recruitment from each facility to ensure that each team member contributes to the project implementation and the sustainability of the project results in the event that some members are transferred to other institutions.' (Health manager at a private facility).

\section{Strengths and limitation of this study}

The objective of the study was clearly stated and a high proportion of the invited respondents participated in the study. This is the first qualitative inquiry study to explore the enablers and barriers of leadership development knowledge transfer in a healthcare context in sub-Saharan Africa. Despite the strengths and contributions of the current study, several potential limitations should be noted. First, the findings are based on data collected from a single training programme thus its interpretation and recommendations are applicable to the ongoing programme, but may not be as relevant to other leadership development interventions. Second, our study employed a qualitative design; hence the findings 
on knowledge transfer enablers and barriers should be cautiously interpreted because they are based on the perceptions and views of health managers; excluding views of team members or institutional team members who cooperated in the project. Third, the study lacked a comparison group, and therefore it is not possible to explicitly conclude that transferability of knowledge occurred as a result of the implementation leadership development practices alone. Fourth, this is a singlesite study and the findings could be only transferred or adapted to similar project-based experiential learning programme interested in transferring knowledge from class to real workplace challenges.

\section{DISCUSSION}

The objectives of this study were to investigate the health manager's experiences and perceptions on factors that facilitate or impede knowledge transfer at the workplace, with intentions of recommending possible strategies and informing policies for enhancing transfer. Although large amounts of money are being invested towards health system strengthening in Africa, including countries such as Kenya, there is little evidence on knowledge transfer and the influencing factors within the workplace. The existing literature has so far identified three main determinants of training transfer: training design or enabling factors, individual factors or trainee characteristics and work environment or transfer climate. ${ }^{12}{ }^{24}$ While these studies reported similar transfer factors to those identified in our study, environment, trainee characteristics and training design were elucidated in their study as key concerns. Pham et $a l^{2122}$ revealed similar concerns on the mediating role of transfer strategies in relation to transfer design and transfer of knowledge. Pham et $a l^{22}$ study place key players of transfer training strategy as trainees, training providers and employers; consequently, their results evidenced work environment factors such as supervisory support, job autonomy and preferred support to be significantly associated with the training transfer. Based on this analysis, the findings suggest that transfer can be improved if enablers and barriers are further unpacked., The aforementioned studies ${ }^{48} 8^{30-33}$ on transfer did not involve participants from the health sector, especially from sub-Saharan Africa. These studies suggested various crucial strategies prerequisite for transfer such as work environment factors, trainee characteristics and training design, and these drivers were also confirmed in our study.

Notwithstanding the growing recognition on capacity building as a health system strengthening intervention in sub-Saharan African countries, the issue of application of new knowledge to real-workplace challenge has been given low priority by health managers, policymakers and training institutions. Yet still, in the era scarce resources, accountability and dynamic business environment, organisations are not able to realise the ROI for training their employees due to underutilisation of learnt knowledge, skills and behaviours. Research evidence suggests that the context under which knowledge is transferred has a great influence on organisational performance. But what do we know about the transfer of leadership knowledge transfer, given the proclaimed importance in relation to our research context? What are the evidence-bases for the claimed transfer factor relevance to project-based experiential learning in healthcare organisations, and specifically in a newly devolved system? In order to comprehensively increase our conceptual understanding on knowledge transfer in a healthcare context, we conducted an in-depth inquiry on transfer determinants including (a) enabling factors, (b) impeding factors and (c) the programmes' alumni propose context-specific strategies for enhancing knowledge transfer during and after the training. This study contributes to that evidence base.

The most recent and comparable cases studies on the impact of leadership on organisational performance in Africa present positive findings on the impact of leadership development on health systems. However, the understanding of how the attained knowledge was transferred from theory to practice at work environment is warranted. The study focused on the views of healthcare managers as the key informants for the research questions addressed. Compared with the aforementioned studies, the participants in this study emphasised additional insights into the training transfer literature. Clear differences emerged between teams with the successful implementation of priority projects and those who failed to implement. Five major enabler themes that illustrate the experiences of the managers emerged. Three of these themes were consistent and largely reflected the established categories represented in the literature for major transfer influences such as Baldwin's and Ford's conceptual model. The differences that affected the ability to transfer knowledge through successful project implementation were primarily issues within the: (i) training design, (ii) trainee characteristics and (iii) work environment. These results are in general agreement with significant standing findings in the area of training knowledge transfers. ${ }^{45}$ Additionally, further analysis led to the emergence of new subthemes such as attitudinal shift, power, position and political goodwill. Two unique themes were; (i) team-based coaching and (ii) occurring opportunities. This echoes findings from Grant ${ }^{43}$ and Peters ${ }^{44}$ which suggest that team coaching has the potential of influencing team performance. Events such as devolution of health systems, endemic strikes in public health systems and political elections were categorised as the subthemes in the occurring opportunities theme. Thus in the successful project teams, there was a conjunction of favourable factors which provided a conducive environment within which knowledge, skills, behaviours and projects could be assimilated to teams operations. This result is in line with Pham and colleagues ${ }^{22}$ and other studies. ${ }^{2} 81416$ The teams who failed to implement their priority projects reported the following constraints: (i) 
inadequate management support in provision of necessary resources for implementation, (ii) inadequate team and staff support, (iii) high staff turnover, (iv) misalignment of board's verses manager's priorities, (v) lack of technical expertise required to implement the projects, (vi) endemic strikes, (vii) negative politics and (viii) poor communication management. In a context of limited resources, our study findings recommendation on transfer strategies imply that for effective knowledge transfer to occur in project-based experiential learning in healthcare organisations, the following factors should be considered: (i) effective allocation and efficient utilisation of resources especially the financial and human resource, (ii) prioritisation of intervention in alignment with organisational priorities, resources and staff input, (iii) effective communication among the stakeholders for buy-in, (iv) longitudinal coaching post-training and (v) training a pre-existing workplace teams.

\section{Implication and further research}

The study findings have implication for individual healthcare managers, training institutions as well as the healthcare policymakers. This study underscores diverse transfer enablers and barrier that need to be considered when designing and integrating knowledge transfer enablers between the classroom and the work environment by the key stakeholder. Further exploration possibly through comparative case studies on context-specific factors could facilitate and enhance the outcome for knowledge transfer in healthcare institutions. This study, therefore, offers new insights perceived relevant by participants especially on emerging factors which seem under-researched in the training transfer literature.

\section{CONCLUSION}

The objectives of this study were to investigate the health manager's perceptions on factors that facilitate or impede knowledge transfer at the workplace, with intentions of informing possible strategies or policies to enhance the transfer. The study findings revealed that for the trained managers to optimally utilise the learnt knowledge and skills, the following contextual constraints should be addressed: (i) inadequate management support in provision of necessary resources for implementation, (ii) inadequate team and staff support, (iii) high staff turnover, (iv) misalignment of board's verses manager's priorities, (v) lack of technical expertise required to implement the projects, (vi) endemic strikes, (vii) negative politics and (viii) poor communication management. These findings, therefore imply that for effective knowledge transfer to occur in project-based experiential learning in healthcare organisations, the following factors should be well-thought-out; (i) when intervening to improve the health systems performance, a needs-driven curriculum based on formative assessment must be espoused so that it is receptive and capable of responding to the different contextual needs, (ii) the need for a robust stakeholder's engagement from multiple domains in order to design the strongest training that drives practices during change, (iii) effective allocation and efficient utilisation of resources especially, the financial and human, (iv) improvement of work climate to encourage open communication and teamwork, (v) training real-world work teams together to ensure team stability and sustainability of the attained results and (vi) incorporating longitudinal coaching beyond the training as a leadership tool through institutionalisation. Such insights have important implications for the approach in training real-world work teams while reinforcing performance improvement at the workplace. Studies like this one can provide meaningful information to help struggling health systems and health managers address their own health services challenges and as a result, trigger attainment of the health goals such as reducing reduced maternal and under-five mortality. This study adds to the extremely limited body of literature on knowledge transfer in leadership development among the healthcare managers in Kenya and sub-Saharan Africa.

Acknowledgements We are grateful to all the Health Managers and their facility teams from all participating Counties in Kenya for sharing their experiences and access to their projects and data. We appreciate academic support from the Institute for Healthcare Management at Strathmore University PhD support group specifically Dr Ben Ngoye, Jackline Aridi, Mary Nyikuri and Eric Tama for their feedback. We appreciate Annie Muisyo for her support in data collection.

Contributors TC was a principal investigator who conceptualised, designed, implemented, analysed and interpreted the data. JO contributed in validating the study objective, literature review, data analysis, interpretation of results and review of the manuscript. GK and JR made a significant contribution in justification of the study, advice on methodology, literature reviews, and identification of themes. They reviewed and suggested modification of drafts and approval of the final manuscript. The first author (TC) led in writing the manuscript and reviewed it based on comments from the other authors. All the authors reviewed and approved the submission of the final manuscript.

Funding The authors have not declared a specific grant for this research from any funding agency in the public, commercial or not-for-profit sectors.

Competing interests None declared.

Patient consent for publication Not required.

Ethics approval Ethical approval to conduct this study was obtained from the Strathmore University ethical review committees (Protocol ID No. SU-IRB 0243/18) and the permit to conduct the study in the counties was obtained from the National Commission for Science, Technology and Innovation (NACOSTI/P/18/21001/23609).

Provenance and peer review Not commissioned; externally peer reviewed.

Data availability statement Data are available in a public, open access repository.

Open access This is an open access article distributed in accordance with the Creative Commons Attribution Non Commercial (CC BY-NC 4.0) license, which permits others to distribute, remix, adapt, build upon this work non-commercially, and license their derivative works on different terms, provided the original work is properly cited, appropriate credit is given, any changes made indicated, and the use is non-commercial. See: http://creativecommons.org/licenses/by-nc/4.0/.

ORCID iD

Tecla Chelagat http://orcid.org/0000-0002-1312-8404

\section{REFERENCES}

1 Peter D, Martha Ray RM. Workplace factors improving performance. Perform Improv Q 1996;9:75-89.

2 Wen ML-Y, Lin DY-C. How supportive transfer climate affects individual's motivation to training transfer. IJLD 2014;4. 
3 Schneier CE. Developing and training human resources in organizations. Acad Manag Rev 2011;8:163-6.

4 Georgenson DL. The problem of transfer calls for partnership. Train Dev Journal 1982;36:75-8.

5 Baldwin TT, Ford JK. Transfer of training: a review and directions for future research. Pers Psychol 1988;41:63-105.

6 Curry DH, Caplan P, Knuppel J. Transfer of training and adult learning (total). J Contin Soc Work Educ 1994;6:8-14.

7 Wexley KN, Latham GP. Developing and training human resources in organizations (Prenticee Hall series in human resources. 3rd Edition. University of Toronto: Person, 2002.

8 Saks AM, Belcourt M. An investigation of training activities and transfer of training in organizations. Hum Resour Manage 2006;45:629-48.

9 Ford JK. Defining transfer of learning: the meaning is in the answers. Adult Learn 1994;5:22-3.

10 Jeffrey M, Foley L. Learning transfer and its Intentionality in adult and continuing education. New Dir Adult Dir Contin Educ 2013;137:6-11.

11 Cheng EWL, Hampson I. Transfer of training: a review and new insights. Int J Manag Rev 2008;10:327-41.

12 Tracey JB, Tannenbaum SI, Kavanagh MJ. Applying trained skills on the job: the importance of the work environment. J Appl Psychol 1995;80:239-52.

13 Blume BD, Ford JK, Baldwin TT, et al. Transfer of training: a metaanalytic review. J Manage 2010;36:1065-105.

14 Rouiller JZ, Goldstein IL. The relationship between organizational transfer climate and positive transfer of training. Hum Resour Dev $Q$ 1993;4:377-90.

15 van der Klink M, Gielen E, Nauta C. Supervisory support as a major condition to enhance transfer. Int $J$ Train Dev 2001;5:52-63.

16 Velada R, Caetano A, Michel JW, et al. The effects of training design, individual characteristics and work environment on transfer of training. Int J Training \& Development 2007;11:282-94.

17 Burke LA, Baldwin TT. Workforce training transfer: a study of the effect of relapse prevention training and transfer climate. Hum Resour Manage 1999;38:227-41.

18 Ford JK, Weissbein DA, Kevin Ford D. Transfer of training: an updated review and analysis. Perform Improv Q 1997;10:22-41.

19 Gollwitzer PM. Implementation intentions: strong effects of simple plans. Amer Psychologist 1999;54:493-503.

20 Machin MA, Fogarty GJ. The effects of self-efficacy, motivation to transfer, and situational constraints on transfer intentions and transfer of training. Performance Improvement Quarterly 2008;10:98-115.

21 Thi N, Pham P, Gijselaers W, et al. Building learning experiences in a changing world, 2011. Available: http://link.springer.com/10.1007/ 978-94-007-0802-0

22 Pham NTP, Segers MSR, Gijselaers WH. Effects of work environment on transfer of training: empirical evidence from master of business administration programs in Vietnam. Int J Train Dev 2013;17:1-19.

23 Hung W. Problem-Based learning: a learning environment for enhancing learning transfer. New Dir Adult Contin Educ 2013;137:28-37.

24 Timothy TB, Kevin JF. Transfer of training: a review and directions for future research. Pers Psychol 1988;41:63-105.

25 Clarke N. Job/work environment factors influencing training transfer within a human service Agency: some indicative support for Baldwin and Ford's transfer climate construct. Int J Train Dev 2002;6:146-62.
26 Lim DH, Johnson SD. Trainee perceptions of factors that influence learning transfer. Int J Train Dev 2002;6:36-48.

27 Obare V, Brolan CE, Hill PS. Indicators for universal health coverage: can Kenya comply with the proposed post-2015 monitoring recommendations? Int J Equity Health 2014;13.

28 DHS. The Kenya demographic and health survey 2015 Kenya National Bureau of Statistics; 2014.

29 Regmi K. Decentralizing health services: a global perspective. New York: Springer, 2014: 1-15.

30 Mills A, Vaughan JP, Smith DL, et al. Health system decentralization: concepts, issues and country experience. World health organisation, 1990. Available: https://books.google.co.uk/books?id= efpfQgAACAAJ

31 World Health Organisation. Management in low income countries. making health systems work, 2007. Available: http://www.who.int/ management/working_paper_10_en_opt.pdf

32 Kimathi L. Challenges of the Devolved Health Sector in Kenya: Teething Problems or Systemic Contradictions? Africa Development 2017;42:55-77.

33 World Health Organisation. Monitoring the building blocks of health systems: a Handbook of indicators and their measurements strategies. Geneva, 2010. http://www.who.int/entity/ workforcealliance/knowledge/toolkit/26.pdf?ua $=1$

34 Peterson EA, Dwyer J, Howze M, et al. Presence of leadership and management in global health programs: Copendium of case studies, 2011.

35 Mansour M, Mansour JB, El Swesy AH. Scaling up proven public health interventions through a locally owned and sustained leadership development programme in rural upper Egypt. Hum Resour Health 2010;8:1.

36 Kwamie A, Dijk Hvan, Agyepong IA. Advancing the application of systems thinking in health: realist evaluation of the leadership development programme for district manager decision-making in Ghana. Health Res Policy Sys 2014;12.

37 Seddiq K, Enarson DA, Shah K, et al. Implementing a successful tuberculosis programme within primary care services in a conflict area using the stop TB strategy: Afghanistan case study. Confl Health 2014;8:3.

38 Seims LRK, Alegre JC, Murei L, et al. Strengthening management and leadership practices to increase health-service delivery in Kenya: an evidence-based approach. Hum Resour Health 2012;10:25

39 Gillham B. Research interviewing: the range of techniques: a practical guide. UK: McGraw-Hill Education, 2005: 119-57.

40 Saks AM. So what is a good transfer of training estimate? A reply to FitzPatrick. Ind Organ phsychologist 2002;39:29-30.

41 Curry L, Taylor L, Chen PG-C, et al. Experiences of leadership in health care in sub-Saharan Africa. Hum Resour Health 2012;10.

42 Day DV. Leadership development: a review in context. The Leadership Quarterly 2000;11:581-613.

43 Grant AM. The efficacy of executive coaching in times of organisational change. J Change Manag 2014;14:258-80.

44 Peters J, Carr C. Team effectiveness and team coaching literature review. Coach An Int J Theory, Res Pract 2013;6:116-36.

45 Burke LA, Hutchins HM. Training transfer: an integrative literature review. Hum Resour Dev Rev 2007;6:263-96. 